\title{
Production of biodiesel from waste cooking oil in a continuous packed bed reactor with an agglomerated Zr-SBA-15/bentonite catalyst
}

\author{
Juan A. Melero ${ }^{1 *}$, L. Fernando Bautista ${ }^{1}$, Jose Iglesias ${ }^{2}$, Gabriel Morales ${ }^{1}$ and Rebeca Sánchez- \\ Vazquez $^{1}$ \\ ${ }^{1}$ Department of Chemical and Environmental Technology \\ ${ }^{2}$ Department of Chemical and Energy Technology \\ Universidad Rey Juan Carlos. C/ Tulipán s/n. Móstoles. E28933. Madrid. Spain \\ *juan.melero@urjc.es
}

Published on:

Applied Catalysis B: Environmental, 145 (2013) 197-204.

http://dx.doi.org/10.1016/j.apcatb.2013.02.050 


\section{Abstract}

Zr-SBA-15 material has been agglomerated with bentonite clay to form a macroscopic structured catalyst with particle sizes of $1.5 \mathrm{~mm}$ with the purpose of being used in the continuous production of biodiesel from waste cooking oil on a packed bed reactor. The influence of different reaction parameters was assessed including methanol to oil molar ratio, residence time and temperature. The pellet-type Zr-SBA-15/bentonite catalyst was highly active in the continuous flow process leading to a steady molar FAME yield of ca. $96 \%$ at 210 o $C$ and 70 bar with a methanol to oil molar ratio of 50:1 and a residence time of $30 \mathrm{~min}$. Longtime on stream experiments revealed an outstanding stability of the Zr-SBA-15 particulate material, since this provided a sustained FAME yield of $96 \%$ for over 260 hours, being negligible the deactivation of the catalyst during this period. Bentonite clay partially contributed to the methanolysis reaction of triglycerides during the early stages of the reaction, but after a short period (1 hour) its influence on the reaction became very low. In this way, the outstanding catalytic performance of the agglomerated catalyst must be attributed mainly to the presence of active acid sites in the the Zr-SBA-15 material. The leaching of metal species ( $\mathrm{Na}, \mathrm{K}, \mathrm{Ca}$ and $\mathrm{Mg}$ ) coming from bentonite binder was low in the outlet effluent. Catalyst did not suffer any significant changes in physicochemical properties after the longtime on stream experiment, preserving zirconium content and acid capacity.

Keywords. Zr-SBA-15, bentonite, packed-bed reactor, biodiesel, waste cooking oil 


\section{Introduction}

Transportation is, together with industry, one of the most energy demanding sectors in developed countries, accounting for one third of the total energy consumption in modern economies, approximately. This huge amount of energy is almost totally based on the use of fossil fuels, mainly oil distillates. However, the reduction of oil resources and their consequent increasing price, the environmental concerns associated to the use of conventional fuels, and the new energy policies giving incentives for the use of sustainable energy resources, have renewed and increased the interest on alternative biofuels for transportation. Nowadays there is a whole collection of different biofuels which can be produced from a huge variety of renewable resources. This large group of fuels ranged from diesel-like fuels obtained through the NexBTL [1] or the Ecofining [2] processes from oleaginous feedstock, showing similar fuel properties than crude oil-derived fuels, to the most diverse oxygenated chemicals obtained from lignocellulosic biomass [3], which have been proposed as alternative fuels. However, from a technical and an economical perspective, already commercial biofuels, such as bioethanol or biodiesel can be considered among the best currently available alternatives to come to the forefront [4].

Biodiesel is conventionally obtained by methanolysis of oleaginous feedstock in presence of alkaline catalysts, due to the inherent high catalytic activity of bases in transesterification reactions under mild conditions. However, this operation mode, using alkaline homogenous catalysts, does not lack of some disadvantages. For instance, the homogeneous nature of these catalysts makes necessary their neutralization after reaction, producing waste salts which are incorporated in the products, so that additional refining and purification steps are mandatory to achieve commercial specifications in the final produced biodiesel. A plausible solution to all these inconveniences is the use of heterogeneous catalysts [5], though the basic nature of the same is also a drawback itself. Basic catalysts react with free fatty acids (FFA), present in lowgrade feedstock, to form soap [6], consuming some fraction of the catalyst and feedstock and leading to downstream processing troubles. These limitations can be overcome either by using high-grade expensive oleaginous feedstock or by conditioning the initial raw material to reduce the FFA content, though both methods involve higher production costs. Many studies have shown that low grade oleaginous feedstock, such as waste cooking oils, rendered animal fats, trap grease, yellow or brown greases, etc. [7], show good potential as raw materials for biodiesel production due to their relative low cost which could enhance the profitability of the process [8]. These raw materials contain saponifiable matter (glycerides and free fatty acids), 
but also water and some other contaminants which will have significant effect on the transesterification reaction [9], especially for the traditional base-catalyzed process. One of the possibilities to limit the negative influence of these impurities is by using heterogeneous acid catalysts. Acid catalysts can simultaneously drive both FFA esterification and triglycerides transesterification reactions, though at the expense of applying harsher reaction conditions. Nevertheless, the use of heterogeneous acid catalysts seems to be beneficial from multiple points of view, as it has been ascertained from the comparison of the technical feasibility and economical viability of several biodiesel production processes [10]. Moreover, packing heterogeneous acid catalysts into packed bed continuous flow reactors allows treating the oleaginous raw material in a continuous manner, enhancing their productivity, while the production costs are minimized and the downstream purification steps are simplified. Despite all these advantages, few investigations dealing with continuous biodiesel production in presence of heterogeneous acid catalysts packed into packed bed reactors have been reported. Thus, Li and co-workers reported the use of an acidic cation-exchange resin, NKC-9, as catalyst for the continuous esterification of a FFA-rich oleaginous feedstock [11],[12]. Though this catalyst evidence good catalytic activity, its performance in transesterification reactions was not assessed. McNeff et al. [13] reported the use of a zirconia-based acidic catalyst in a packed bed reactor to drive rapid esterification and transesterification reactions under very harsh reaction conditions. Though the catalyst did not evidence deactivation, the high temperature and pressure required for the transformation is a major negative point of this catalytic system. This has been partially solved by Ng et al. [14], who reported the use of a new generation of zirconia supported metal oxide incorporating $\mathrm{Zn}$ species to accomplish good catalytic properties in the conversion of highly acidic feedstocks into FAME.

As an alternative to these processes, here we propose the use of Zr-SBA-15 [15], a quite robust heterogeneous acid catalyst, able to transform a multitude of low-grade oleaginous feedstock into biodiesel with minimum activity decay, even in presence of high amounts of impurities [16]. Since Zr-SBA-15 is obtained as a powder, its casting into particulated material is mandatory to avoid an extremely high pressure drop. In this way, we have applied one of our previously reported methods for the agglomeration and extrusion of powdered catalysts into particulated material [17]. Along these lines, as a follow up work, we report the effect of the agglomeration process on the catalyst, its final physicochemical properties, its performance in FAME production from low-grade waste cooking oil as well as the stability of the catalyst in long-time on stream assays in a continuous packed bed reactor. 


\section{Experimental}

\subsection{Materials and methods}

Tetraethylorthosilicate (TEOS, Aldrich) and zirconocene dichloride $\left(\mathrm{Cp}_{2} \mathrm{ZrCl}_{2}, \mathrm{ABCR}\right)$ were used as silicon and zirconium precursor, respectively, for the synthesis of Zr-SBA-15. The structuredirecting agent was the block copolymer Pluronic P-123 ((PEO) $)_{20}(\mathrm{PPO})_{70^{-}}(\mathrm{PEO})_{20}$, Aldrich). Bentonite natural clay (Bentonil, Gadorgel, supplied by Süd-Chemie) was used as binding agent and methyl cellulose (Aldrich) was employed as additive to control the plasticity of the mixed catalyst-clay-water in the agglomeration of Zr-SBA-15 samples. Waste cooking oil supplied by the refectory of the Campus (Universidad Rey Juan Carlos, Móstoles) was used after filtration in the catalytic test experiments. Table 1 summarizes the main properties of the oleaginous feedstock whereas Table 2 shows the chemical composition of the bentonite binder.

\subsection{Synthesis of Zr-SBA-15 material}

Zr-SBA-15 material was synthesised following a procedure previously reported in literature [16], using zirconocene dichloride as metal precursor under synthesis conditions previously optimized. In a typical synthesis, $4 \mathrm{~g}$ of Pluronic P-123 was dissolved in $125 \mathrm{ml}$ of $0.67 \mathrm{~N}$ hydrochloric acid at room temperature. After complete dissolution, $1.2 \mathrm{~g}$ of zirconocene dichloride was added to the solution, allowing the mixture to get clear after 3 hours of gentle stirring at $40{ }^{\circ} \mathrm{C}$. Then, $8.63 \mathrm{~g}$ of TEOS were added into the synthesis medium and the suspension was agitated for 20 hours. The final suspension was hydrothermally aged at $130{ }^{\circ} \mathrm{C}$ under static conditions for $24 \mathrm{~h}$ and the material was recovered by filtration. The surfactant occluded in the porous structure of the Zr-SBA-15 material was removed by calcination at 450 ${ }^{\circ} \mathrm{C}$ in air for 5 hours.

\subsection{Agglomeration of Zr-SBA-15}

Agglomeration of powdered Zr-SBA-15 has been performed using our previously reported method based on the use of clays as binding agents [17]. The powdered Zr-SBA-15 acid catalyst was mixed with bentonite ( $30 \% \mathrm{wt})$, methyl cellulose $(5 \% \mathrm{wt})$ and ultra pure water. The resultant mixture was kneaded under high shear conditions in a kneading-extruder (Lleal AME) during 3 hours to achieve a homogeneous mixture. After the solid paste was conditioned in a damp atmosphere, it was extruded in a laboratory-sized mini-screw extruded (Caleva Extruder 20) to form uniform rods (diameter of $1.5 \mathrm{~mm}$ ). The rod-shaped agglomerate was then dried in 
a drying chamber fitted with a humidity controller. Thereafter, dried rods were calcined in air at $450 \circ \mathrm{C}$ for 2 hours using a slow heating ramp of $1.8{ }^{\circ} \mathrm{C} \mathrm{min}^{-1}$ in order to achieve a gradual removal of water and organic species and strengthening the mechanical consistency of the material by sintering of the inorganic binder. The final Zr-SBA-15 pellets were obtained by cutting the rod extruded material into particles with ca. $1.5 \mathrm{~mm}$ of length (Figure 2).

\subsection{Catalyst characterization}

The zirconium content present in Zr-SBA-15 materials, both as powder and agglomerated samples, was measured by ICP-OES from digested samples in water. The textural properties of the Zr-SBA-15 based materials were evaluated through $\mathrm{N}_{2}$ adsorption-desorption isotherms, recorded on a Micromeritics Tristar 3000 unit at 77K. XRD patters were recorded on a Philips $X^{\prime}$ Pert diffractometer to assess the ordering degree of the samples, using the $\mathrm{Cu} \mathrm{K \alpha}$ line in the $2 \theta$ angle range of $0.6-5^{\circ}$.

\subsection{Catalytic tests}

Catalytic reaction runs were driven in a continuous $120 \mathrm{~cm}$ length $-0.9 \mathrm{~cm}$ inner diameter packed bed reactor fitted with flow, pressure, and temperature controllers. Figure 1 depicts a simplified flowchart of the packed bed reactor and auxiliary equipment. The catalytic bed was loaded with $28 \mathrm{~g}$ of particulate catalyst. Several catalytic runs at different residence times were carried out for the methanolysis of waste cooking oil. The distinct effects of the temperature conditions as well as the methanol to oil molar ratio were assessed in the ranges $150-210^{\circ} \mathrm{C}$ and $10-50$ for the methanol to oil molar ratio. Methanol and oil were pumped, using HPLC pumps, into a mixing chamber where the mixture was heated to reach the reaction temperature before being injected into the reactor.

The residence time $\left(t_{R}\right)$ of the liquid phase in the packed bed reactor was calculated as the ratio between the volume of the liquid phase inside the reactor $\left(V_{L}\right)$ and the flow of the reactants $\left(Q_{L}\right)$ as it is expressed in equation 1 .

$$
t_{R}=\frac{v_{L}}{Q_{L}}=\frac{v_{B} \cdot \varepsilon_{L}}{Q_{L}}
$$

where $V_{B}$ is the empty bed volume and $\varepsilon_{L}$ is the porosity of the bed. The porosity represents the fraction of void to bed volume and it has been experimentally determined by immersing the catalytic bed in methanol. The temperature of the system was controlled inside the 
reactor, whereas the pressure was maintained at 70 bar to ensure liquid phase conditions. The effluent solution was expanded in a flash vessel, kept at $65^{\circ} \mathrm{C}$ under vacuum to facilitate the removal of methanol, and transferred to a decanter to allow the separation of the glycerol and FAME layers. The yield of fatty acid methyl esters (FAME) from fatty acid alkyl chains was calculated by ${ }^{1} \mathrm{H}$ NMR analysis [18]. 


\section{Results and discussion}

This contribution is devoted to the agglomeration of a powdered Zr-SBA-15 acid catalyst, in order to cast it into a particulate solid able to be loaded in an up-flow packed bed reactor to be used in the methanolysis of a low-grade oleaginous feedstock, such as waste cooking oil. The research comprises the application of an agglomeration method for Zr-SBA-15 materials and the catalytic testing of the resultant particulate solid in a packed bed reactor under different operation conditions.

\subsection{Agglomeration of Zr-SBA-15}

The agglomeration of the Zr-SBA-15 material was accomplished using a previously reported method for the agglomeration of powdered catalysts [17]. This method is based on the use of water, natural clay (bentonite) acting as binding agent, and methyl-cellulose to control the plasticity of the Zr-SBA-15/Clay/Water mixture. The mixture, which is a paste, is kneaded and extruded to cast cylindrical rods ( $1.5 \mathrm{~mm}$ diameter of) which are then calcined and broken into small pieces (particle size of 1,5 mm, Figure 2) to be loaded into the packed bed reactor. Table 3 depicts the physic-chemical properties of both the powdered material and the Zr-SBA-15 material after agglomeration.

With regards to the metal content, both catalysts, either as a powder or as agglomerated material, displayed a similar zirconium loading, though this was slightly lower in the later. This reduction of the metal loading, when agglomerating the powder, finds its origin in the dilution of the Zr-SBA-15 catalyst because $30 \% \mathrm{wt}$ of $\mathrm{Zr}$-free bentonite was used to form the paste to cast the particulate solid. Similarly, when comparing the acidity of both catalysts (Table 3 ), ammonia TPD experiments reveal a significant reduction of the acidity. Again, the observed reduction, $30 \%$ of the starting acid loading, corresponds to the dilution of the catalyst with the bentonite clay (note that ammonia TPD of bentonite showed a negligible acid capacity). Hence, it can be concluded that the agglomeration of the powder Zr-SBA-15 material do not lead to any damage both in the metal as well as in the acid loading of the mesostructured material.

In order to evaluate the structural integrity of the Zr-SBA-15 materials, X-ray diffraction patterns at low and high angle values have been recorded for both the powder and the agglomerated mesostructured catalysts (Figure 3). The characteristic hexagonal array of pores in the pmm6 symmetry, typical from SBA-15 materials, is evident at low angle values (Figure $3 \mathrm{~A})$ and it is well preserved, though the intensity of the diffractions slightly diminished after 
the agglomeration of the catalysts. The presence of crystalline zirconium silicate (zircon) species, which are present in the starting Zr-SBA-15 material, is also observed in the agglomerated material (Figure 3B), and these seems not to be significantly affected by the agglomeration process. In conclusion, the structure of the Zr-SBA-15 material seems to be well preserved during the agglomeration procedure.

Textural properties measured by $\mathrm{N}_{2}$ adsorption-desorption analysis are listed in Table 3 . In this case, unlike to the metal content, the textural properties of the particulate material are, with the exception of the pore diameter which remains almost constant, much lower than those calculated for the starting powdered sample. Figure 4 depicts the nitrogen adsorptiondesorption isotherms recorded for both materials, both as absolute and relative isotherms. In the first case, the observed reduction in the porosity is clearly evident, since the adsorbed pore volume reached by the isotherm is substantially lower for the agglomerated material. This difference between both samples is translated into a decrease in both surface area and pore volume (Table 3). However, the large diminishing of both parameters cannot be explained in terms of the simple dilution of the mesostructured material with clay binding agent. This reduction could be ascribed to the shrinkage and collapse of the some fraction of the porous structure during the agglomeration of the $\mathrm{Zr}-\mathrm{SBA}-15$ material, though the invariance of the mean pore size -this is slightly reduced, Table 3 and Figure $4 \mathrm{~A}$ inset- does not support this option. In addition, the comparison of the relative adsorption-desorption isotherms (Figure 4B) evidences the lack of significant differences between both samples, suggesting that the reduction of the porosity caused in the overall porous structure of the starting Zr-SBA-15 material is not specifically in the microporous or the mesoporous systems. Thus, the most probably cause of the reduction in porosity is the sintering of the inorganic binder and Zr-SBA15 silica particles after agglomeration and thermal treatment, since pore blockage is discarded due to the preservation of the acid loading of Zr-SBA-15 in the agglomerated material. Nevertheless, the final material still displays large mesopores and surface area so providing good catalytic activity for biodiesel synthesis through methanolysis of oleaginous feedstock.

\subsection{Catalytic performance of agglomerated Zr-SBA-15 in the methanolysis of waste cooking oil in a continuous packed bed reactor.}

The pelletized Zr-SBA-15/clay material has been catalytically tested in the packed bed reactor outlined in Figure1. Loading of the catalysts into the reaction cylinder was carefully accomplished trying to avoid de formation of erosion-derived fine powders that would 
considerably elevate the pressure drop through the bed of catalyst pellets. Additionally, a protection system consisting of a glass wool pad complemented by small glass spheres was placed in the reactor outlet to minimize downstream clogging. For each experiment, reactants were conditioned to the selected reaction temperature in a mixing pre-chamber before being fed to the catalytic bed. In order to achieve a correct flow through the catalytic bed at the reaction temperature, and additionally ensuring liquid phase for the volatile methanol, pumping inlet pressure was packed at 70 bar. The experimental range of reaction conditions (bed temperature, residence time, and feed methanol/WCO molar ratio) were based on our previous works with the same catalytic active phase, i.e. the mesostructured zirconiummodified SBA-15 silica (Zr-SBA-15), in batch-mode [16]. Therein we performed a dual optimization analysis -of both the catalyst's synthesis and the reaction conditions- using surface response methodology, selecting the yield towards FAME as main response factor, and using highly acidic crude palm oil as substrate. The optimized reaction conditions in batch resulted to be $209^{\circ} \mathrm{C}, 12.45 \mathrm{wt} \%$ catalyst's loading based on oil weight, and 45.8 methanol to oil molar ratio. Under these optimized conditions molar FAME yield reached 92 mol\% after 6 hours of reaction in batch mode. Moreover, we showed that such a high catalytic activity achieved with crude palm oil was retained when using, among other low-cost materials, waste cooking oil (WCO), the raw material in the present continuous study. Taking that into account, we carried out a series of experimental sessions with the packed bed set-up under steady state conditions -typically less than $2 \mathrm{~h}$ were necessary to achieve a sufficiently steady state. The results are summarized in Figure 5, showing the profiles of molar yield to FAME versus time on stream under varying operation conditions.

In a first set of continuous catalytic runs the temperature and fed $\mathrm{MeOH} / \mathrm{WCO}$ molar ratio were fixed at those values corresponding to the above-mentioned optimization in batch-mode, $210^{\circ} \mathrm{C}$ and 50:1 MeOH/oil, whereas the residence time was varied from $15 \mathrm{~min}$ to $60 \mathrm{~min}$ (Figure 5A; liquid hourly space velocity, LHSV from $4 \mathrm{~h}^{-1}$ to $1 \mathrm{~h}^{-1}$ ). The catalytic results indicate that under these conditions a residence time of $30 \mathrm{~min}\left(\mathrm{LHSV}=2 \mathrm{~h}^{-1}\right.$ ) is enough to reach a steady molar yield to FAME over $95 \%$. This FAME value is unexpectedly high as compared with our previous work on batch-mode, where 6 hours were needed to achieve a lower $92 \%$ yield. Such an enhancement of the catalytic activity may be attributed to a better contact of reactants and the catalytic solid. Nevertheless, the potential catalytic role of the binder clay should also be assessed (see below). Further lowering of the residence time up to 15 minutes $\left(\mathrm{LSHV}=4 \mathrm{~h}^{-1}\right)$ leaded to a significant decrease of the steady FAME yield (ca. $\left.65 \%\right)$. These 
catalytic results clearly indicate that a residence time over 30 minutes is required to enhance both external diffusion and the intrapore diffusion process [19].

In a second set of experiments, we sought to settle whether a reduction of the temperature level was feasible. Aside energy economics considerations, a reduction in the temperature level in this catalytic system would allow significantly reducing the operating pressure, thus increasing the overall profitability of the potential industrial application. Figure $5 \mathrm{~B}$ includes the experimental sessions performed under different bed temperatures, $150^{\circ} \mathrm{C}, 180^{\circ} \mathrm{C}$ and $210^{\circ} \mathrm{C}$, fixing the $\mathrm{MeOH} / \mathrm{WCO}$ molar ratio at 50:1, and the residence time in $30 \mathrm{~min}$. As shown, the temperature impacts on the methanolysis of WCO dramatically. When temperature was 210 oC the molar FAME yield reached ca. $95 \%$ under steady conditions. In contrast, when the temperature was lower the molar FAME yield did not come up a satisfactory value $(50 \%$ for

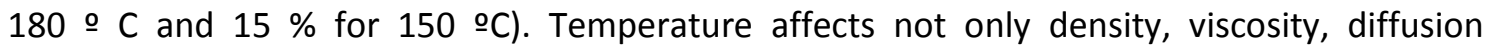
coefficient, mass transfer coefficients of each component or liquid mixture but also adsorption equilibrium constant, rate constant and the reaction equilibrium constant of transesterification which makes this reaction parameter to play a crucial role in the catalytic performance of the system. It must be noted that probably a lower temperature, such as $180 \circ \mathrm{C}$, would benefit from longer residence times to achieve higher yields. However, in this system the enlargement of the residence time is limited (by flowability hindrances, separation of phases, etc.).

Figure $5 \mathrm{C}$ includes the results from the study of varying the MeOH/WCO molar ratio, keeping constant the temperature $\left(210^{\circ} \mathrm{C}\right)$ and the residence time $(30 \mathrm{~min})$. The objective was to evaluate the effect of lowering the amount of methanol used, eventually aiming to reduce the recovering and recycling necessities. However, as shown in the figure, a molar ratio of 25:1 yielded a reduction of the steady-state yield to FAME down to $70 \%$, whereas a lower value of 10:1 led to null activity of the system. These results can be explained by the fact that the transesterification is an equilibrium reaction and a high molar methanol to oil ratio is needed to shift the reaction towards the FAME production.

Hence, according to the experiments optimum conditions for our packed bed reactor were: residence time of 30 minutes, molar ratio of methanol to oil of 50 and temperature of $210 \cong \mathrm{C}$.

In view of the high FAME yield achieved in the packed-bed methanolysis of WCO over the pelletized Zr-SBA-15-based catalyst, concerns arose about the possible catalytic role of the clay used for the agglomeration of the catalyst. Table 2 summarizes the chemical composition of the bentonite. Among the different species, there is a significant contribution of alkaline earth 
metal oxides, mainly $\mathrm{MgO}$ but also some $\mathrm{CaO}$, which are known heterogeneous base catalysts for the transesterification of triglycerides [20]. These base catalysts could easily contribute to the catalytic activity masking the true acid-catalytic performance of the zirconium sites placed in the Zr-SBA-15 catalyst. Hence, in order to further assess the catalytic role of the binder clay, a blank reaction was carried out using a bed of pelletized calcined bentonite, without Zr-SBA15 component. The reaction conditions were those providing the highest FAME yields in the previous studies, i.e. $210 \circ \mathrm{C}, 30 \mathrm{~min}$ residence time, $50: 1 \mathrm{MeOH} / \mathrm{WCO}$ molar ratio. Figure 6 depicts the comparison between the FAME yield results achieved, under the optimized reaction conditions, in presence of pelletized Zr-SBA-15 and bentonite. Whereas the mesostructured-based material provides a sustained FAME yield above $95 \%$ for the overall experiment ( 6 hours), bentonite only leads to moderate FAME yields for the first two hours (75\%), and afterwards the FAME yield abruptly drops to $31 \%$. Bentonite thus appears to slightly contribute to the catalysis of the methanolysis of WCO, but only during the early stages of the reaction. However, $\mathrm{Zr}$ sites in Zr-SBA-15 catalysts are the main responsible of the high activity shown by the agglomerated catalyst.

Leaching of metallic species from the bentonite binder should be taken into consideration not only for their contribution in a homogenous catalysis but also for the contamination of the outlet FAME effluent. Therefore, the reaction effluent was analyzed looking for the presence of metals by means of ICP-OES. For this purpose, several samples were collected during a catalytic experiment and these were rotaevaporated to remove the excess of methanol. The two resultant layers -FAME and glycerol- were independently analyzed accordingly to standards EN ISO 14107 and EN ISO 14538, to quantify the amount of P, Na, K, Ca and Mg in the product effluent. Whereas concentration below the quantification limit $(0.001 \mathrm{mg} / \mathrm{kg})$ were detected in the glycerol layer, FAME provided quantifiable concentrations of $\mathrm{P}, \mathrm{Mg}, \mathrm{Ca}$, $\mathrm{Na}$ and $\mathrm{K}$, though their concentration resulted too low -below $0.5 \mathrm{mg} \cdot \mathrm{kg}^{-1}$ for $\mathrm{Na}+\mathrm{K}$, and below $2 \mathrm{mg} \cdot \mathrm{kg}^{-1}$ for $\mathrm{P}$ and for $\mathrm{Ca}+\mathrm{Mg}$ to significantly impact on the progress of the reaction (it must also be noted that the starting waste cooking oil also has some metals, see Table 1). The very low concentration of these impurities in the product stream, below those limits required by biodiesel standards such as the European standard ISO 14214, makes unnecessary a downstream purification process for their removal, confirming the beneficial effect of using a heterogeneous acid catalyst in the simplification of the biodiesel production process from low grade feedstock. 
In order to check the stability of the catalyst and its resistance against deactivation phenomena, a long-time on stream experiment was carried out, comprising 260 hours of continuous operation. Figure 7 depicts the FAME yield results monitored during the overall experiment. Results confirm that particulate Zr-SBA-15 material is a quite robust and active catalyst in biodiesel production form waste cooking oil, since no evidence of catalytic deactivation is detected during the whole experiment. On average, the substrate stream is converted to provide $96 \%$ of FAME yield, which is sustained during the overall catalytic text. After time of stream, the agglomerated catalyst was recovered and without any treatment was analyzed to check the integrity of the physicochemical properties. Unless for the textural properties, the physico-chemical properties obtained by the characterization of the used catalyst (Table 3), are quite close to those obtained for the fresh particulate material, confirming the good stability of this catalyst. Mass zirconium loading of $7.2 \%$ and acid capacity of $0.171 \mathrm{mmol} \mathrm{H}^{+}$per gram was obtained for the used catalyst which evidence that metal content and acid sites concentration of the Zr-SBA-15 catalyst were preserved after the catalytic cycle. In the case of the textural properties, the differences found between the fresh and the used particulate catalysts were ascribed to some loss in the microporous fraction of the pelletized material. This fraction of the porous structure of the SBA-15 materials does not play any important role in the conversion of bulky substrates such as triglycerides, and thus, this variation between the fresh and the used samples does not affect the catalytic performance of the pelletized Zr-SBA-15 material.

\section{Conclusions}

An agglomerated Zr-SBA-15/bentonite catalyst was applied in a packed bed reactor to catalyze the transesterification of WCO to FAME. The reaction parameters including methanol to oil molar ratio, residence time and temperature influence dramatically on the catalytic performance affecting in the reaction-mass transfer behaviors of continuous catalytic transesterification. Hence, for this particular system, optimum conditions were proposed as residence time of 30 minutes (LHSV of $2 \mathrm{~h}^{-1}$ ), molar ratio of methanol to oil of 50 and temperature of 210 C which allowed a steady molar FAME yield of $95 \%$ with a low leaching of metallic species from bentonite binder and a very high stability of acid sites of Zr-SBA-15 catalyst. Long-time on stream catalytic test revealed a very high catalyst stability and resistance against deactivation phenomena. The catalytic performance of pelletized Zr-SBA-15 materials is well preserved for at least 260 hours of continuous operation in a packed bed reactor without evidence of catalytic activity decay. 


\section{Acknowledgements}

Financial supports by Spanish Government MICINN (project CTQ2008-01396) and Regional Government of Madrid through the project S2009-ENE1743 are gratefully acknowledged. 


\section{References}

[1] a) M. Snåre, P. Mäki-Arvela, I.L. Simakova, J. Myllyoja, D.Y. Murzin, Russ. J. Phys. Chem. B, 3 (2009) 1035. b) V. Markkanen, P. Lindquist, E. Harlin, P. Aalto, J. Myllyoja, V. Alopaeus, Process for the manufacture of hydrocarbons of biological origin, World Patent N 934 A1 (2010).

[2] a) T. Kalnes, T. Marker, D.R. Shonnard, Int. J. Chem. Reactor Eng., 5 (2007) Article A48. b) F. Baldiraghi, M. di Stanislao, G. Faraci, C. Perego, T. Marker, C. Gosling, P. Kokayeff, T. Kalnes, R. Marinangeli: Ecofining: New process for green diesel production from vegetable oil in F. Cabani, G. Centi, S. Perathoner, F. Trifirò (Eds.): Sustainable Industrial Catalysis, Wiley-VCH Verlag, Weinheim, 2009.

[3] G.J.M. Gruter, F. Dautzenberg, European Patent N. 1,834,950 (2007). b) G.J.M. Gruter, F. Dautzenberg, European Patent N. 2,050,742 (2007). c) O. Casanova, S. Iborra, A. Corma, J. Catal., 275 (2010) 236. d) B.C. Windom, T.M. Lovesteda, M. Mascal, E.B. Nikitin, T.J. Bruno, Energy Fuels, 25 (2011) 1878. e) I.T. Horváth, H. Mehdi, V. Fábos, L. Boda, L.T. Mika, Green Chem., 10 (2008) 238

[4] R. Luque, J.A. Melero, Advances in Biodiesel Production: Process and Technologies, Ed. Woodhead Publishing, Cambridge, 2012.

[5] Y. Ren, B. He, F. Yan, H. Wong, Y. Cheng, L. Lin, Y. Feng, J. Li, Bioresource Technol., 113 (2012) 19.

[6] D.Y.C. Leung, X. Wu, M.K.H. Leung, Appl Energ., 87 (2010) 1083.

[7] J. Iglesias, G. Morales: Biodiesel from waste oils and fats: methods and catalysis in R. Luque, J.A. Melero (Eds.): Advances in Biodiesel Production: Process and Technologies, Ed. Woodhead Publishing, Cambridge, 2012.

[8] Z.J. Predojevic, Fuel, 87 (2008) 3522.

[9] G. Morales, L.F. Bautista, J.A. Melero, J. Iglesias, R. Sánchez-Vázquez, Bioresour. Technol., 20 (2011) 9571.

[10] a) A. H. West, D. Posarac and N. Ellis, Bioresour. Technol., 99 (2008) 6587. b) J. M. Marchetti, V. U. Miguel and A. F. Errazu, Fuel Process. Technol., 89 (2008) 740.

[11] Y. Feng, A. Zhang, J. Li, B. He, Bioresour. Technol., 102 (2011) 3607.

[12] Y. Cheng, Y. Feng, Y. Ren, X. Liu, A. Gao, G. He, F. Yang, J. Li, Bioresour. Technol., 113 (2012) 65. 
[13] C.V. McNeff, L.C. McNeff, B. Yan, D.T. Nowlan, M. Rasmussen, A.E. Gyberg, B.J. Krohn, R.L. Fedie, T.R. Hoye, Appl. Catal. A: General, 343 (2008) 39.

[14] M. Kim, C. DiMaggio, S.O. Salley, K.Y.S. Ng, Bioresour. Technol., 118 (2012) 37.

[15] J. Iglesias, J.A. Melero, L.F. Bautista, G. Morales, R. Sánchez-Vázquez. Catal. Today, 167 (2011) 46-55.

[16] J.A. Melero, L.F. Bautista, J. Iglesias, G. Morales, R. Sánchez-Vázquez, Catal. Today, 125 (2012) 44.

[17] J.A. Melero, J. Iglesias, J. Sainz-Pardo, P. de Frutos, S. Blázquez. Chem. Eng. J., 139 (2008) 631.

[18] G. Gelbard, O Brés, R.M. Vargas, F. Vielfaure, U.F. Schuchardt, J. Am. Oil Chem. Soc., 72 (1995) 1239.

[19] Y. Xiao, L. Gao, G. Xiao, B. Fu, L. Niu, Ind. Eng. Chem. Res., 51 (2012) 11860.

[20] A.A. Refaat, Int. J. Environ. Sci. Tech., 8 (2011) 203. 
Table 1. Properties of waste cooking oil (WCO) used as reaction feedstock.

\begin{tabular}{|c|c|c|c|}
\hline Property & Analytical method & Units & Value \\
\hline Acid value & UNE EN ISO 660:2000 & $\mathrm{mg}_{\mathrm{KOH}} / \mathrm{g}$ & 4.06 \\
\hline Density @40ㄷ & UNE EN ISO 3675:1999 & $\mathrm{kg} / \mathrm{m}^{3}$ & 918 \\
\hline Viscosity @40ㄷ & UNE EN ISO 3104:1996 & $\mathrm{mm}^{2} / \mathrm{s}$ & 66.5 \\
\hline \multirow[t]{4}{*}{ Metals content } & ASTM D-5185:2009 & $\mathrm{mg} / \mathrm{kg}$ & \\
\hline & $P$ & & 3.1 \\
\hline & $\mathrm{Ca}+\mathrm{Mg}$ & & 0.5 \\
\hline & $\mathrm{Na}+\mathrm{K}$ & & 2.8 \\
\hline Water content & UNE EN ISO 12937:2001 & $\mathrm{mg} / \mathrm{kg}$ & 1398 \\
\hline Unsaponifiable mater & Plank \& Lorbeer (1994) & $w t \%$ & 1.0 \\
\hline
\end{tabular}


Table 2. Chemical composition of the bentonite used for the agglomeration of Zr-SBA-15 catalyst (on a dry basis).

\begin{tabular}{cccccccccc}
\hline Compound & $\mathrm{SiO}_{2}$ & $\mathrm{Al}_{2} \mathrm{O}_{3}$ & $\mathrm{Fe}_{2} \mathrm{O}_{3}$ & $\mathrm{TiO}_{2}$ & $\mathrm{MgO}$ & $\mathrm{CaO}$ & $\mathrm{Na}_{2} \mathrm{O}$ & $\mathrm{K}_{2} \mathrm{O}$ & Others \\
\hline Mass $\%{ }^{\mathrm{a}}$ & 54.8 & 8.8 & 3.1 & 0.8 & 18.2 & 1.0 & 2.3 & 1.8 & 9.2 \\
\hline
\end{tabular}


Table 3. Physico-chemical properties of Zr-SBA-15-based catalysts, before and after the agglomeration treatment and catalytic run.

\begin{tabular}{lcccccc}
\hline Sample & $\begin{array}{c}\mathrm{Zr}^{\mathrm{a}} \\
(\% \mathbf{w t})\end{array}$ & $\begin{array}{c}\mathbf{H}^{+\mathbf{b}} \\
(\mathbf{m e q} / \mathbf{g})\end{array}$ & $\begin{array}{c}\mathrm{S}_{\mathrm{BET}}{ }^{\mathrm{c}} \\
\left(\mathbf{m}^{2} / \mathbf{g}\right)\end{array}$ & $\begin{array}{c}\mathrm{Vp}^{\mathrm{d}} \\
\left(\mathbf{c m}^{3} / \mathbf{g}\right)\end{array}$ & $\begin{array}{c}\mathrm{Dp}^{\mathrm{e}} \\
(\AA)\end{array}$ & $\begin{array}{c}\mathrm{a}_{\mathbf{0}}{ }^{\mathrm{f}} \\
(\AA)\end{array}$ \\
\hline Powder & 9.7 & 0.275 & 531 & 1.407 & 128 & 136 \\
Pellet (Fresh) & 7.1 & 0.187 & 335 & 0.799 & 124 & 134 \\
Pellet (Used) & 7.2 & 0.171 & 201 & 0.665 & 123 & 135 \\
\hline
\end{tabular}

${ }^{a}$ Metal loading calculated by means of ICP-OES; ${ }^{b}$ Acid loading calculated by $\mathrm{NH}_{3}$ temperature programmed desorption analysis; ${ }^{\mathrm{C}}$ Specific Surface area calculated by the B.E.T. method; ${ }^{\mathrm{d}}$ Total pore volume recorded at $\mathrm{p} / \mathrm{p} 0=0.985 ;{ }^{e}$ Mean pore size calculated as the maximum of the B.J.H. pore sizes distribution applying the K.J.S. correction; ${ }^{f}$ Unit cell size calculated as $2 /\left(\mathrm{V} 3 \cdot \mathrm{d}_{100}\right)$, where $\mathrm{d}_{100}$ is the Bragg's lattice parameter. 


\section{Figure Captions}

Figure 1. General scheme of the packed bed reactors with side equipments used for the continuous transesterification of oleaginous feedstock.

Figure 2. Images of the $\mathrm{Zr}$-SBA-15 material before after the casting by agglomeration. A) Powdered catalyst, B) Agglomerated material.

Figure 3. X-ray diffraction patterns recorded for Zr-SBA-15 materials at A) low angle and B) high angle values.

Figure 4. Nitrogen adsorption desorption analysis recorded for powdered and agglomerated Zr-SBA-15 materials. A) Specific isotherms and pore size distributions (inset) and B) Relative isotherms.

Figure 5. Yield to FAME profiles versus time on stream obtained in the packed-bed reactor charged with pelletized Zr-SBA-15/bentonite catalyst operating under steady-state conditions. A) Influence of the residence time (at 210ㄷ, and 50:1 MeOH/WCO molar ratio); B) influence of the temperature (at 50:1 molar ratio, and $30 \mathrm{~min}$ residence time); C) influence of the $\mathrm{MeOH} / \mathrm{WCO}$ molar ratio (at $210^{\circ} \mathrm{C}$, and 30 min residence time).

Figure 6. Comparison between FAME yields achieved in presence of particulate $\mathrm{Zr}$-SBA-15 and bentonite under optimized reaction conditions $\left(210^{\circ} \mathrm{C}, \mathrm{MeOH} / \mathrm{WCO}=50: 1\right.$, and $30 \mathrm{~min}$ residence time).

Figure 7. FAME yield profile of a long-time on stream catalytic test performed under optimized reaction conditions $\left(210^{\circ} \mathrm{C}, \mathrm{MeOH} / \mathrm{WCO}=50: 1\right.$, and 30 min residence time). 


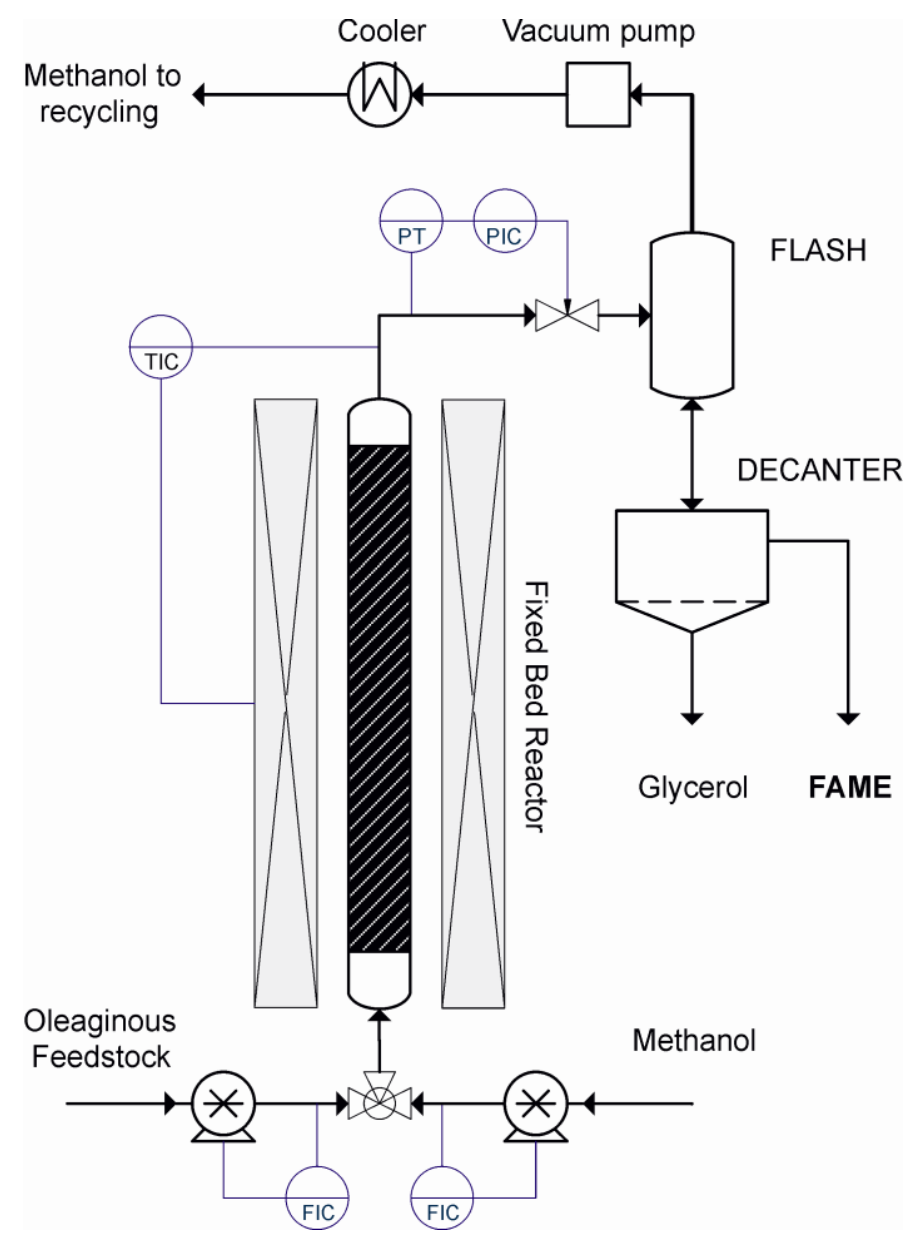

Figure 1

J.A. Melero et al. 

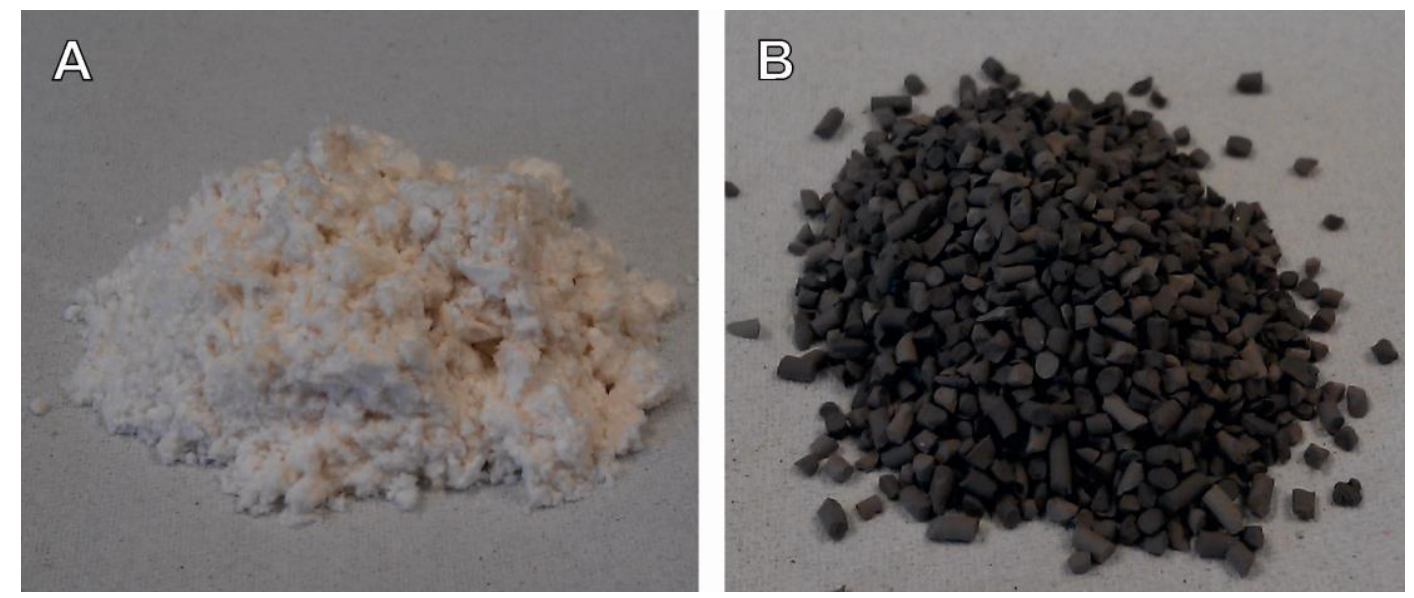

Figure 2

J.A. Melero et al. 

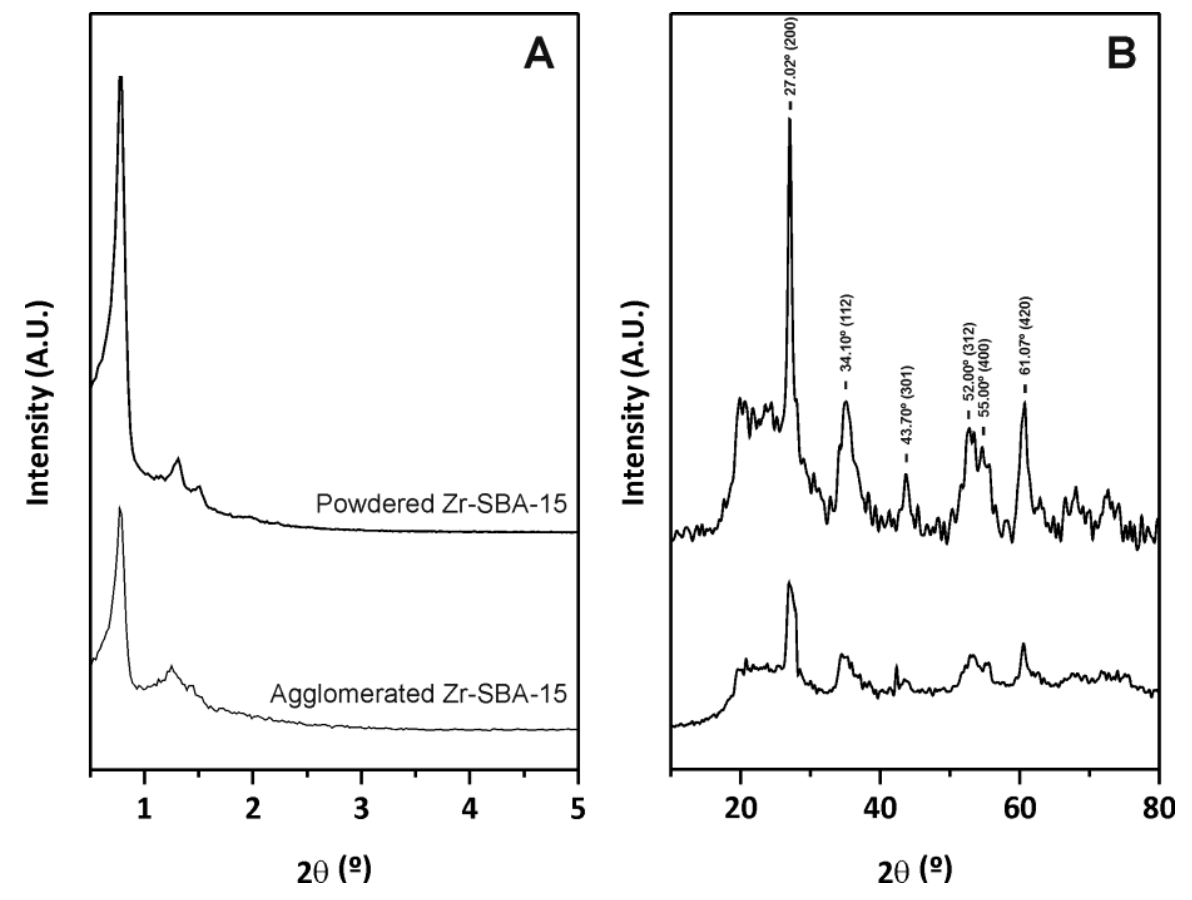

Figure 3

J.A. Melero et al. 

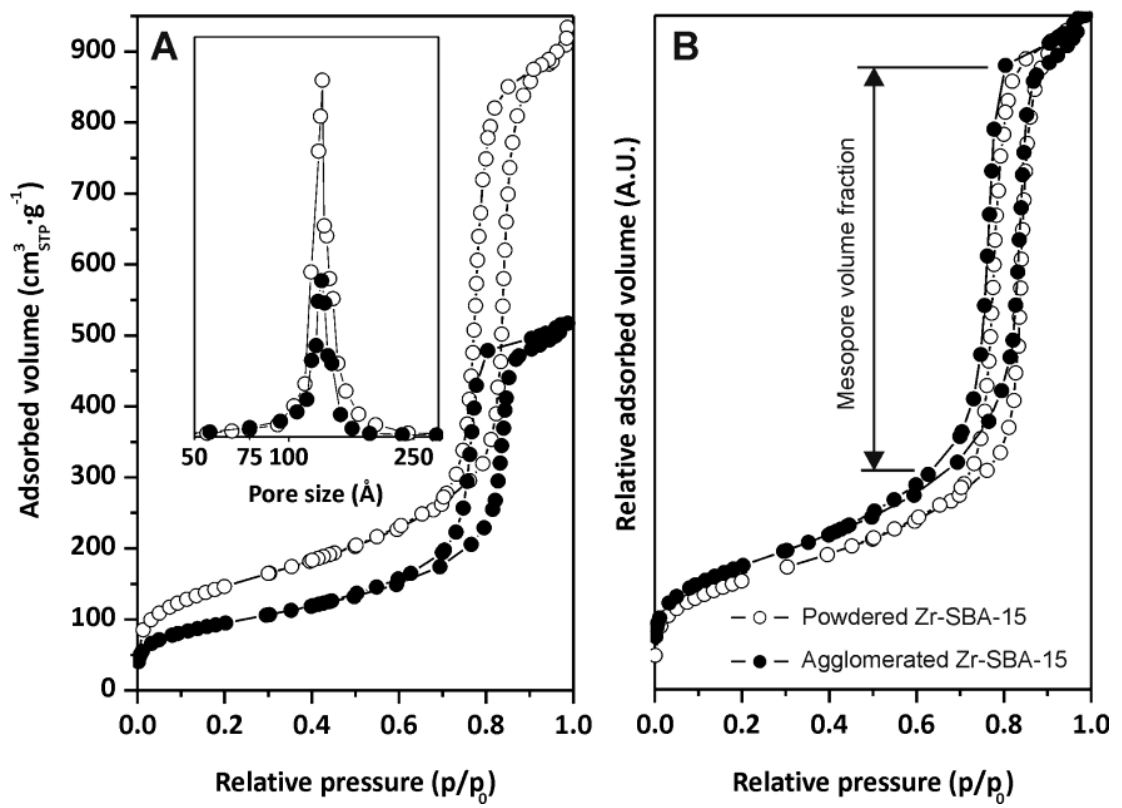

Figure 4

J.A. Melero et al. 


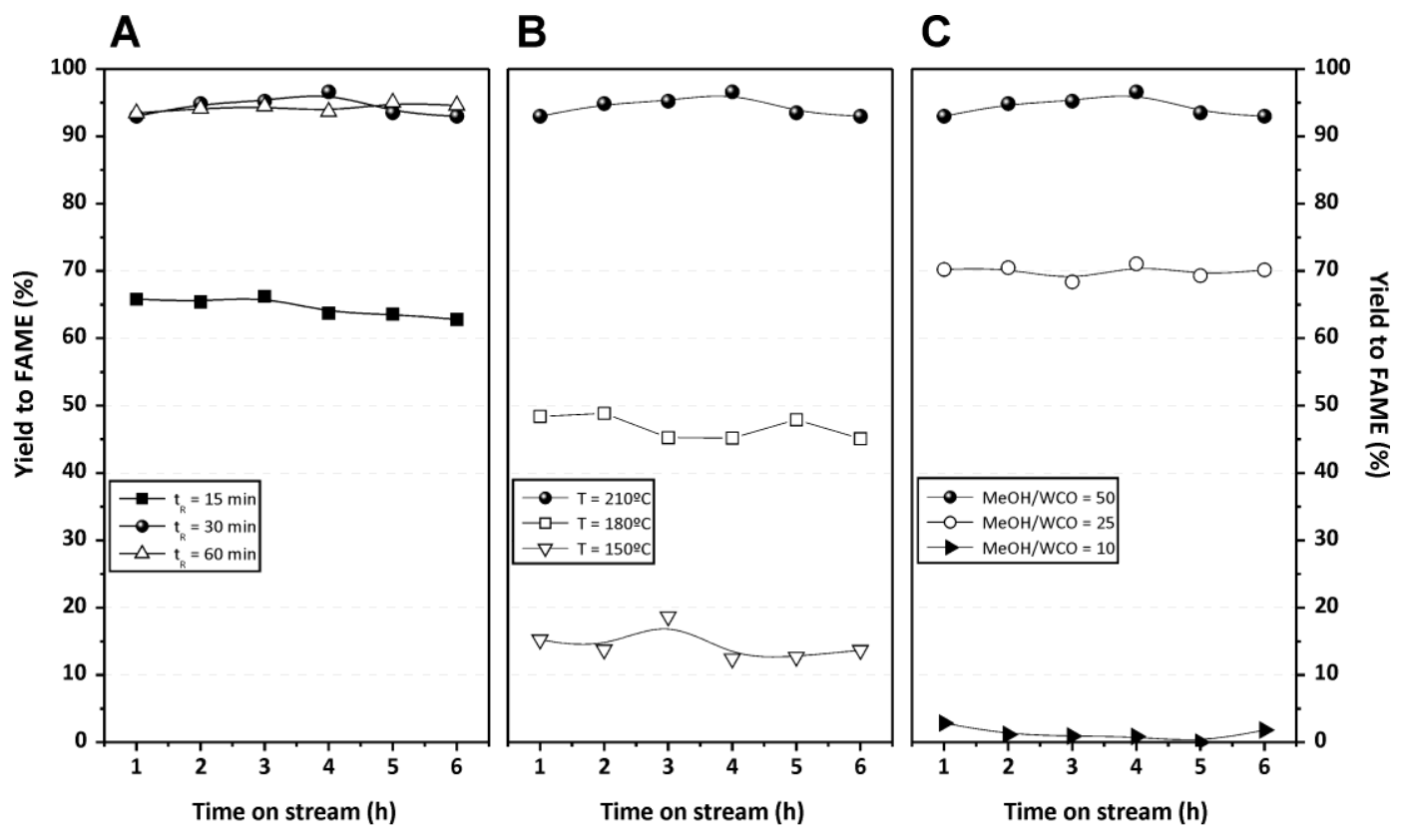

Figure 5

J.A. Melero et al. 


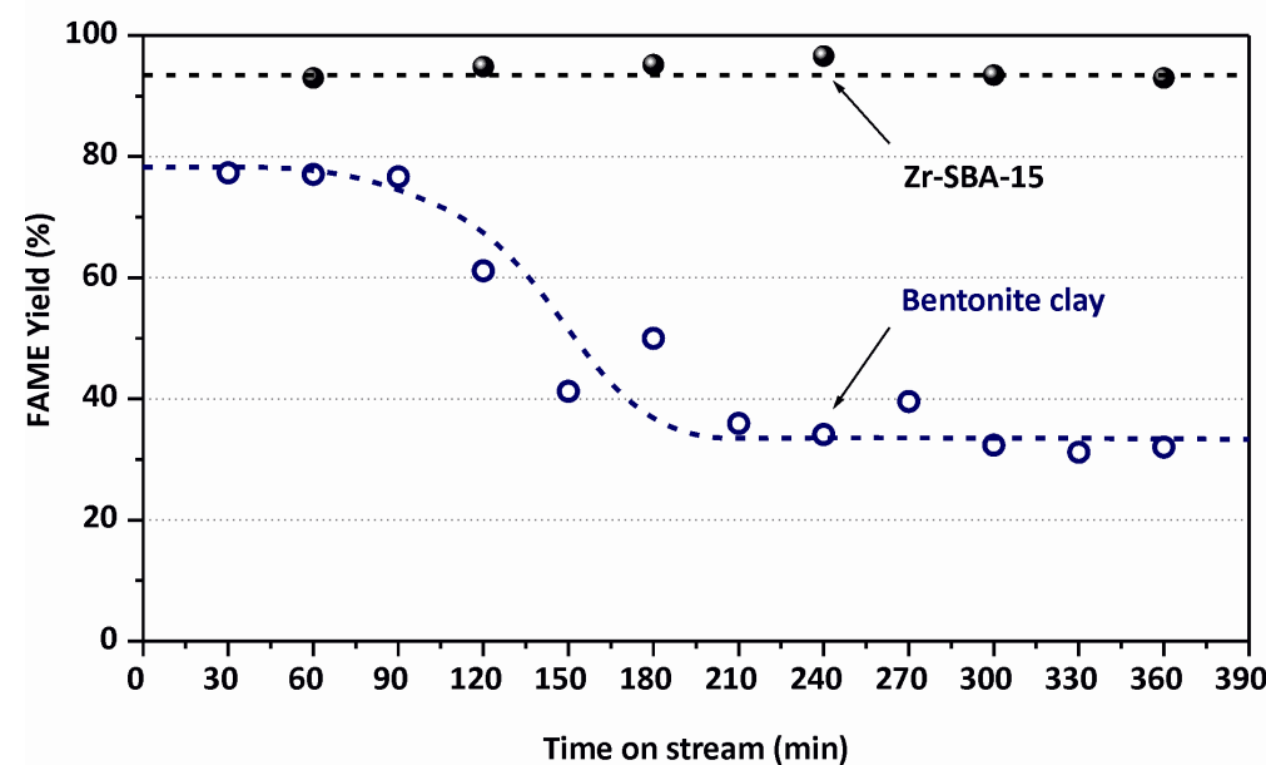

Figure 6

J.A. Melero et al. 


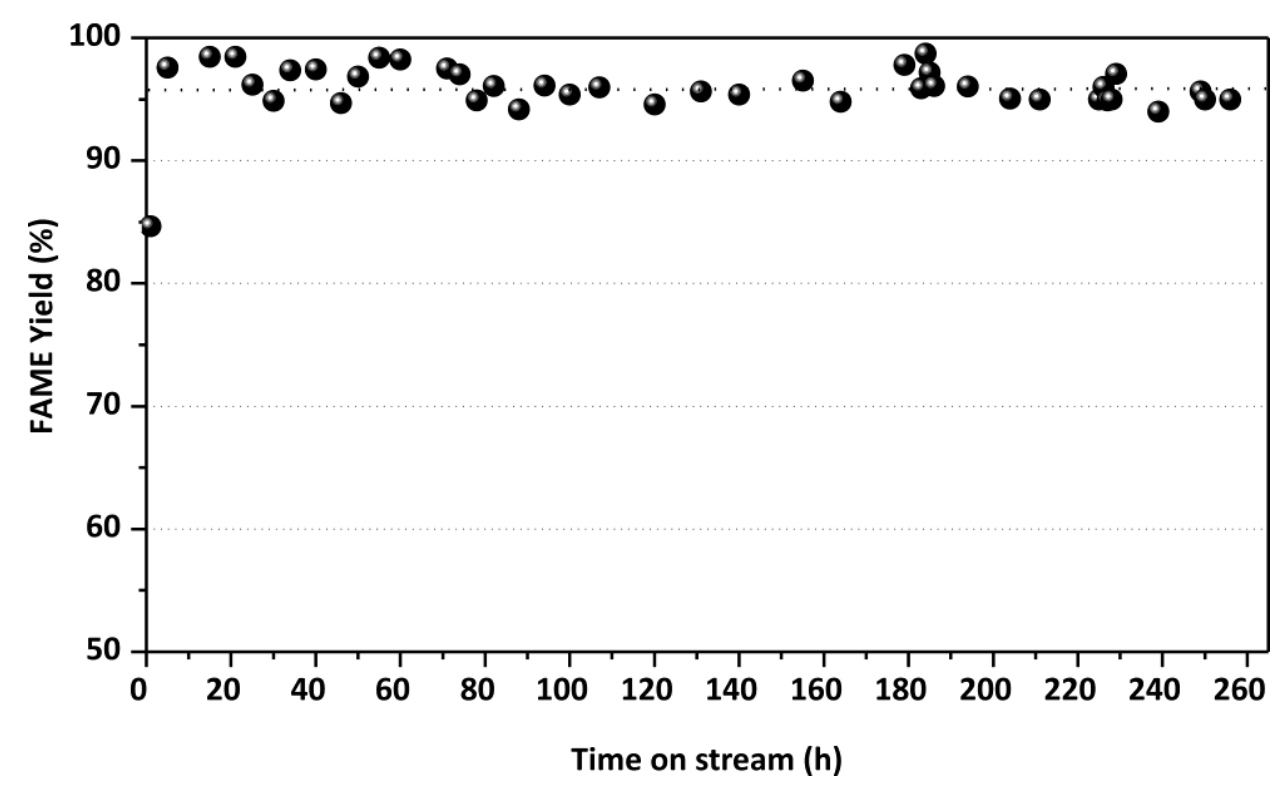

Figure 7

J.A. Melero et al. 